\title{
Review
}

\section{Do You Still Use Topical Antibiotics after Intravitreal Injections?}

\author{
Banu Turgut Öztürk, MD, MSc* \\ Department of Ophthalmology, Selcuk University, Tıp Fakültesi GözHastalklar, A.D. Kampüs 42075, Konya, Turkey \\ "Corresponding author \\ Banu Turgut Oztürk, MD, MSc \\ Proffesor, Faculty of Medicine, Department of Ophthalmology, Selcuk University, Tıp Fakültesi GözHastalıkları, A.D. Kampüs 42075, Konya, Turkey; \\ Tel. 0090332 2244559; Fax.0090 332 2244544; E-mail: ozturkbanuturgut@yahoo.com
}

Article information

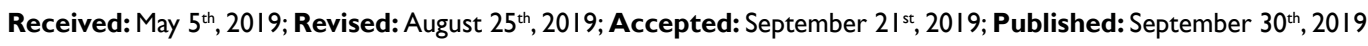

Cite this article

Öztürk BT. Do you still use topical antibiotics after intravitreal injections? Ophthalmol Open J. 2019;3(I):5-9. doi: I0.17।40/OOJ-3-II7

\begin{abstract}
|
Nowadays intravitreal drug injection is the most frequent treatment for retinal diseases. Despite widely use endophthalmitis is already most feared complication of every intravitreal injection in each patient. In clinical setting topical antibiotics have been widely used as a precaution to prevent endophthalmitis however recent published evidence showed it to be unnecessary. Furthermore repeated use of topical antibiotics might give rise to antibiotic resistance in conjunctival flora and thus more aggressive endophthalmitis. Strict asepsis has been awarded as the main rule for endophthalmitis prophylaxis intravitreal injection.
\end{abstract}

\section{Keywords}

Intravitreal injection; Steroid; Anti-vascular endothelial growth factor (VEGF); Topical antibiotic; Enodphthalmitis; Antibiotic resistance.

\section{INTRODUCTION}

$\mathrm{I}$ ntravitreal injections have become the main treatment modality for retinal diseases all over the world. Anti-vascular endothelial growth factor (VEGF) drugs and to a lesser extent steroid implants have made intravitreal injection the most frequent procedure in ophthalmology. The anti-VEGF era began in 2004 with the approval of the first pharmacologic agent for inhibition of VEGF. ${ }^{1,2}$ Till that time the intravitreal injection was an uncommon procedure and many guidelines were advicing the use of pre- and postinjection topical antibiotics to prevent endophthalmitis which was the most feared complication. ${ }^{3}$ The initial randomized clinical trial protocols evaluating the efficacy of anti-VEGF agents mandated also topical antibiotics following intravitreal drug injection. Additionally, product informations of anti-VEGF agents included recommendations for topical antibiotic use as well. ${ }^{4}$ However, the exponential increase in the number of intravitreal injections evidenced a lower incidence of endophthalmitis than expected ranging between $0.01-0.26 \%$ in several studies. ${ }^{5-12}$ This raises questions about the necessity of pre- or post-injection topical antibiotic use.

The practice of using topical antibiotics was actually adopted from other intraocular procedures like cataract surgery. In surgical procedures there exists a surgical wound that may not be completely sealed. However, in intravitreal injections there isn't such a wound as a 30-gauge or at the largest 27-gauge needdle is used. This was probably the main reason for the lower endophthalmitis rate.

\section{PRE-INJECTION ANTIBIOTIC USE |}

Most endophthalmitis cases related to intravitreal injections showed that the causative organism in post-injection endophthalmitis is usually inoculated at the time of injection rather than subsequent entry to the eye. Therefore, needle penetration into a nutrient-rich body cavity warrants pre-cautions that should be taken during the procedure to avoid contamination. ${ }^{13}$ Pre-injection antibiotic use was found logical untill studies showed that povidoneiodine immediately prior to injection revealed less positive bacterial cultures compared to pre-treatment antibiotic use. ${ }^{14,15}$ Two studies also revealed higher risk for endophthalmitis in patients using prophylactic antibiotics. The mechanism has been thought to be the increased ratio of antibiotic-resistant surface bacteria or the detrimental effect of repeated fluoroquinolone use on ocular surface health. ${ }^{6,16}$ 


\section{POST-INJECTION ANTIBIOTIC USE}

As mentioned above post-injection topical antibiotic use was also a query. First in 2004 Aeillo et $\mathrm{al}^{3}$ postulated that post-injection antibiotics did not decrease endophthalmitis incidence. Recently the outcome of numerous large retrospective studies evaluating thousands of injections presented in Table 1 showed no benefit to prevent endophthalmitis. ${ }^{6,8,11,12,16}$ In contrast, some of them found higher rates of endophthalmitis in patients using topical antibiotics. ${ }^{5,6,9,17-22}$ A www.DRCR.net study reported endophthalmitis rate to be $0.13 \%$ in the group receiving topical antibiotics and $0.03 \%$ in the group without antibiotic. ${ }^{18}$ This was attributed to resistant organisms due to antibiotic overuse. ${ }^{23}$ The comparison of agerelated macular degeneration treatments trials (CATT) study also showed no significant difference in endophthalmitis rates between groups with and without antibiotic use. ${ }^{24}$

\begin{tabular}{|c|c|c|c|c|}
\hline \multirow[b]{2}{*}{ Study } & \multirow[b]{2}{*}{ Prophylaxis } & \multirow[b]{2}{*}{ Drug } & \multicolumn{2}{|c|}{ Endophthalmitis Rate } \\
\hline & & & With AB & $\begin{array}{l}\text { Without } \\
\text { AB }\end{array}$ \\
\hline Meyer $^{45}$ & Post-injection & Anti-VEGF,TA & $2 / 860$ & $0 / 984$ \\
\hline Bhatt $^{18}$ & Post-injection & Anti-VEGF,TA & $5 / 2287$ & $5 / 2480$ \\
\hline Cheung $^{19}$ & Post-injection & Anti-VEGF,TA & $5 / 8259$ & $4 / 7636$ \\
\hline Falavarjani ${ }^{20}$ & Post-injection & Anti-VEGF & $6 / 3975$ & 01926 \\
\hline Casparis 46 & Post-injection & Anti-VEGF & $2 / 13234$ & $1 / 26777$ \\
\hline Ramel $^{47}$ & Post-injection & Anti-VEGF,TA & $3 / 10144$ & $3 / 1306$ \\
\hline Stranak $^{48}$ & Pre+post-injec. & Anti-VEGF,TA & $2 / 2651$ & $1 / 2355$ \\
\hline $\mathrm{Li}^{28}$ & Pre+post-injec. & $\begin{array}{l}\text { Anti-VEGF,TA, } \\
\text { Dex, Ocriplasmin }\end{array}$ & $6 / 16984$ & $11 / 53345$ \\
\hline Falavarjani ${ }^{49}$ & Post-injection & Anti-VEGF & $|/ 277|$ & $0 / 5266$ \\
\hline Meredith $^{24}$ & Pre+post-injec. & Anti-VEGF & $8 / 16509$ & $3 / 2000$ \\
\hline Pachuo $^{50}$ & Post-injection & Anti-VEGF & $0 / 310$ & $0 / 310$ \\
\hline Bhavsar $^{51}$ & Pre+post-injec. & Anti-VEGF,TA & $6 / 11565$ & $3 / 17208$ \\
\hline Storey ${ }^{21}$ & Post-injection & Anti-VEGF & $28 / 57654$ & $24 / 89825$ \\
\hline
\end{tabular}

\section{STEROID INJECTION}

Among intravitreally injected drugs steroids have distinctive features than anti-VEGFs. The most frequently used steroid-dexamethasone intravitreal implant (Allergan, Inc., Irvine, CA, USA) has a 22-Gauge needle and additionally steroids give rise to the tendency for infections. ${ }^{25}$ Therefore, steroid injections are expected to require a different approach than anti-VEGF drugs. However, retrospective studies and meta-analysis were surprising. A retrospective study evaluating 3593 dexamethasone implant injections without pre- or post-antibiotic use suggests that an endophthalmitis is a rare event as anti-VEGF injections. ${ }^{26}$ Another metaanalysis evaluating 13 studies and approximately 350.000 injections assessed that type of antibiotic, type of drug injected or antibiotic prophylaxis regimen neither influence endophthalmitis rate nor reduce its incidence. ${ }^{27} \mathrm{~A}$ significant number of triamcinolone and dexamethasone injections were enrolled in this meta-analysis.
Many retrospective studies also reported similar endophthalmitis risks for both anti-VEGF and steroid implants. However, most of them evaluated a smaller number of steroid injections compared to anti-VEGF injections. ${ }^{9,28}$ This should be kept in mind when evaluating this outcome.

\section{WHY ARE TOPICAL ANTIBIOTICS UNNECESSARY? |}

The distinctive feature of intravitreal injections compared to other invasive ophthalmic procedures is the repeated application. The ocular surface was thought to be sterile for years due to the presence of lysozyme, antimicrobial peptides, immunoglobulin A (IgA) complement and other substances. Local bacteria on the ocular surface maintain ocular immunity but transient disruption of bacteria via antibiotics results in a reduction in immune-related mechanisms. ${ }^{29}$ Additionally, the repeated use of short term topical antibiotics increases the resistance of the ocular surface organism to antibiotics. ${ }^{19,30}$ This has been clearly demonstrated in the study of Kim et al. ${ }^{31}$ After 1-year monthly intravitreal injection, the treated eyes using topical antibiotics had increased bacterial resistance compared to untreated fellow control eyes. ${ }^{31}$ Moss et al ${ }^{15}$ reported the rate of positive bacterial culture as $8 \%$ in patients using preoperative antibiotic and povidone-iodine and $4 \%$ in the group receiving povidone-iodine only. Another study compared conjunctival cultures of the injected eye following the use of several topical antibiotics with the fellow untreated eye. Cultures proved multidrug resistance of coagulase-negative staphylococci between 67.5$81.8 \%$ to antibiotics used. As conjunctival flora is presumed the source of post-injection endophthalmitis, this outcome has severe implications. ${ }^{23}$ The drug resistance caused by repeated antibiotic use is not only limited to the eye. It has also impact on the drug resistance in nasopharyngeal flora which may give rise to soft tissue infections and pneumonia. ${ }^{31}$

A confounding factor related to antibiotic use is it's limited penetration to vitreous. Only about $1 / 100.000^{\text {th }}$ of the drug observed in tear fluids reaches the retina and choroid. ${ }^{32}$ So it is impossible to reach the minimum inhibitory concentration in vitreous required to prevent microorganism proliferation after intravitreal injection. ${ }^{33}$

\section{MEASURESTO PREVENT ENDOPHTHALMITIS}

Certainly, some prophylactic measures are warranted to minimize the risk of endophthalmitis following intravitreal injection. Recent evidence shows the use of povidone-iodine installation as the safest way for ocular surface preparation before injection. ${ }^{34}$ Povidoneiodine is a disinfectant and antiseptic agent commonly used for pre-operative preparation in ophthalmic procedures and provides broad-spectrum fast-acting microbicidal activity. It is applied to lids and lashes in 5\% concentration. In contrast to repeated topical antibiotics ocular surface preparation using povidone-iodine $5 \%$ without antibiotic use does not promote bacterial resistance. ${ }^{35} \mathrm{~A}$ study evaluating daily use of povidone-iodine for peritoneal dialysis exit sites reported no resistance. ${ }^{36} \mathrm{Hsu}$ et $\mathrm{al}^{34}$ also reported no antibiotic resistance even no significant alteration resulting from povidone-iodine $5 \%$ for ocular preparation. Povidone-iodine is ad- 
viced to be instilled as the last drop before injection and should be allowed to stay for at least 30 -seconds or more. ${ }^{37}$ Dropping it after lid retraction has been shown to decrease the risk of endophthalmitis 7 folds. ${ }^{38}$ Povidone-iodine with $10 \%$ showed no significant difference with povidone-iodine $5 \%$ in endophthalmitis risk and it may cause greater corneal toxicity and discomfort (Table 2). ${ }^{39}$

\begin{tabular}{l}
\hline Table 2. Precautions Before Intravitreal Injection Procedure \\
\hline Use of Povidone-iodine for Intravitreal Injection \\
\hline$\% 5$ concentration preferred \\
Last drop before injection \\
Put a drop after lid retraction \\
Wait at least for 30 -seconds or more \\
\hline
\end{tabular}

\section{CONCLUSION}

In light of these informations most of the authorities are trending away from topical antibiotic use following intravitreal injections. ${ }^{40}$ The www.DRCR.net and CATT advice to abandon the use of topical antibiotics as frequent use of antibiotics appear to promote the emergence of microbial resistance. ${ }^{24,41}$ American Academy of Ophthalmology (AAO) and also Royal College of Ophthalmology (RCOphth) also discourage the use of antibiotics after intravitreal injections in their guidelines. ${ }^{42-44}$ These are strong scientific evidence to justify a jury that antibiotics are no longer required postinjection if an injection-related endophthalmitis would be brought to a court of law as a medicolegal suit. Using povidone-iodine $5 \%$ without topical antibiotic appears to be the safest approach to avoid the widespread problem of increasing antibiotic resistance. We have to keep in mind to instill it as the last drop possibly after lid retraction and wait for at least 30-seconds.

\section{REFERENCES}

1. Campbell RJ, Bronskill SE, Bell CM, Paterson JM, Whitehead M, Gill SS. Rapid expansion of intravitreal drug injection procedures, 2000 to 2008: A population-based analysis. Arch Ophthalmol. 2010; 128(3): 359-362. doi: 10.1001/archophthalmol.2010.19

2. Keenan TD, Wotton CJ, Goldacre MJ. Trends over time and geographical variation in rates of intravitreal injections in England. Br J Ophthalmol. 2012; 96(3): 413-418. doi: 10.1136/bjophthalmol-2011-300338

3. Aiello LP, Brucker AJ, Chang S, et al. Evolving guidelines for intravitreal injections. Retina. 2004; 24(5 Suppl): S3-S19. doi: 10.1097/00006982-200410001-00002

4. Genentech Inc. Lucentis $10 \mathrm{mg} / \mathrm{ml}$ solution for injection. highlights of prescribing information. San Francisco, CA, USA. Web site. https://www.medicines.org.uk/emc/product/307/smpc. Accessed September 22, 2016.

5. Sigford DK, Reddy S, Moolineaux C, Schaal S. Global reported endophthalmitis risk following intravitreal injections of antiVEGF: A literature review and analysis. Clin Ophthalmol. 2015; 9:

\section{3-781. doi: 10.2147/OPTH.S77067}

6. DossarpsD, Bron AM, Koehrer P, Aho-Glele LS, CreuzotGarcher C, FRCR net. Endophthalmitis after intravitreal injections: incidence, presentation, management and visual outcome. Am J Ophthalmol. 2015; 160(1): 17-25e1. doi: 10.1016/j.ajo.2015.04.013

7. McCannel CA. Meta-analysis of endophthalmitis after intravitreal injection of anti-vascular endothelial growth factor agents: Causative organisms and possible prevention strategies. Retina. 2011; 31(4): 654-661. doi: 10.1097/IAE.0b013e31820a67e4

8. Mosfeghi AA, Rosenfeld PJ, Flynn JW Jr, et al. Endophthalmitis after intravitreal vascular [corrected] endothelial growth factor antagonists: A six year experience at a university referral center. Retina. 2011; 31(4): 662-668. doi: 10.1097/IAE.0b013e31821067c4

9. Bhavsar AR, Googe JM, Stockdale CR, et al. Risk of endophthalmitis after intravitreal drug injection when topical antibiotics are not required: The diabetic retinopathy clinical research network laser-ranbizumab-triamcinolone clinical trials. Arch Ophthalmol. 2009; 127(12): 1581-1583. doi: 10.1001/archophthalmol.2009.304

10. Mason JO $3^{\text {rd }}$, White MF, Feist RM, et al. Incidence of acute onset endophthalmitis following intravitreal bevacizumab (Avastin) injection. Retina. 2008; 28(4): 564-567. doi: 10.1097/ IAE.0b013e3181633fee

11. Pilli S, Kotsolis A, Spaide RF, et al. Endophthalmtiis associated with intravitreal anti-vascular endothelial growth factor therapy injections in an office setting. Am J Opbthalmol. 2008; 145(5): 879882. doi: 10.1016/j.ajo.2007.12.036

12. Fintak DR, Shah GK, Blinder KJ, et al. Incidence of endophthalmitis related to intravitreal injection of bevacizumab and ranibizumab. Retina. 2008; 28(10): 1395-1399. doi: 10.1097/ IAE.0b013e3181884fd2

13. Hunyor AP, Merani R, Darbar A, Korobelnik JF, Lanzetta P, Okada AA. Topical antibiotics and intravitreal injections. Acta Ophthalmol. 2018; 96(5): 435-441. doi: 10.1111/aos.13417

14. Halachmi-Eyal O, Lang Y, Keness Y, Miron D. Preoperative topical moxifloxacin $0.5 \%$ and povidone-iodine $5.0 \%$ versus povidone iodine $5 \%$ alone to reduce bacterial colonization in the conjunctival sac. J Cataract Refract Surg. 2009; 35(12): 2109-2114. doi: 10.1016/j.jcrs.2009.06.038

15. Moss JM, Sanislo SR, Ta CN. A prospective randomized evaluation of topical gatifloxacin on conjunctival flora in patients undergoing intravitreal injections. Ophthalmology. 2009; 116(8): 14981501. doi: 10.1016/j.ophtha.2009.02.024

16. Benoistd'Azy C, Pereira B, Naughton G, Chiambaretta F, Dutheil F. Antibioprophylaxis in prevention of endophthalmitis in intravitreal injection: A systematic review and meta-analysis. PLoS One. 2016; 11(6): e0156431. doi: 10.1371/journal.pone.0156431 
17. Bhavsar AR, Stockdale CR, Ferris FL $3^{\text {rd }}$, et al. Update on risk of endophthalmitis after intravitreal drug injections and potential impact of elimination of topical antibiotics. Arch Ophthalmol. 2012; 130(6): 809-810. doi: 10.1001/archophthalmol.2012.227

18. Bhatt SS, Stephen KE, Joshi K. Prophylactic antibiotic use after intravitreal injection: Effect on endophthalmitis rate. Retina. 2011; 31(10): 2032-2036. doi: 10.1097/IAE.0b013e31820f4b4f

19. Cheung CS, Wong AW, Lui A, Kertes PJ, Devenyi RG, Lam WC. Incidence of endopthalmitis and use of antibiotic prohylaxis after intravitreal injections. Ophthalmology. 2012; 119(8): 1609-1614. doi: 10.1016/j.ophtha.2012.02.014

20. Falavarjani KG, Modarres M, Hashemi M, et al. Incidence of acute endophthalmitis after intravitrealbevacizumab injection in a single clinical center. Retina. 2013; 33(5): 971-974. doi: 10.1097/ IAE.0b013e31826f0675

21. Storey P, Dollin M, Pitcher J, et al. The role of topical antibiotic prophylaxis to prevent endophthalmitis after intravitreal injection. Ophthalmology. 2014; 121(1): 283-289. doi: 10.1016/j.ophtha.2013.08.037

22. Bhavsar AR, Sandler DR. Eliminating antibiotic prophylaxis for intravitreal injections: A consecutive series of 18839 injections by a single surgeon. Retina. 2015; 35(4): 783-788. doi: 10.1097/ IAE.0000000000000392

23. Kim SJ, Toma HS. Antimicrobial resistance and ophthalmic antibiotics: 1-year results of a longitidunal controlled study of patients undergoing intravitreal injections. Arch Ophthalmol. 2011; 129(9): 1180-1188. doi: 10.1001/archophthalmol.2011.213

24. Meredith TA, McCannel CA, Barr C, et al. Postinjectionendophthalmitis in the comparison of age-related macular degeneration treatment trials (CATT). Ophthalmology. 2015; 122(4): 817-821. doi: 10.1016/j.ophtha.2014.10.027

25. Gupta A, Sun JK, Silva PS. Complications of intraviterous injections in patients with diabetes. 2018; 33(1): 42-50. doi: 10.1080/08820538.2017.1353811

26. Stem MS, Todorich B, Yonekawa Y, Capone A Jr, Williams GA, Ruby AJ. Incidence and Visual Outcomes of Culture-Proven Endophthalmitis Following Dexamethasone Intravitreal Implant. JAMA 2017; 135(4): 379-382.

27. Menchini F, Toneatto G, Miele A, Donati S, Lanzetta P, Virgili G. Antibiotic prophylaxis for preventing endophthlamitis after intravitreal injection: A systematic review. Eye (Lond). 2018; 32(9): 1423-1431. doi: 10.1038/s41433-018-0138-8

28. Li AL, Wykoff CC, Wang R, et al. Endophthalmitis after intravitreal injection: Role of prophylactic topical ophthalmic antibiotics. Retina. 2016; 36(7): 1349-1356. doi: 10.1097/ IAE.0000000000000901
29. St Leger AJ, Desai VJ, Drummond RA, et al. An ocular commensal protects against corneal infection by driving an interleukin-17 response from mucosal $\gamma \delta \mathrm{T}$ cells. Immunity. 2017; 47(1): 148-158. doi: 10.1016/j.immuni.2017.06.014

30. Dave SB, Toma HS, Kim SJ. Changes in ocular flora in eyes exposed to ophthalmic antibiotics. Ophthalmology. 2013; 120(5): 937941. doi: 10.1016/j.ophtha.2012.11.005

31. Kim SJ, Toma HS, Midha NK, Cherney EF, Recchia FM, Doherty TJ. Antibiotic resistance of conjunctiva and nasopharynx evaluation study: A prospective study of patients undergoing intravitreal injections. Ophthalmology. 2010; 117(12): 2372-2378. doi: 10.1016/j.ophtha.2010.03.034

32. Trimawithana TR, Young S, Bunt CR, Green C, Alany RG. Drug delivery to the posterior segment of the eye. Drug Discov Today. 2011; 16(5-6): 270-277. doi: 10.1016/j.drudis.2010.12.004

33. Costello P, Bakri SJ, Beer PM, et al. Vitreous penetration of topical moxifloxacin and gatifloxacin in humans. Retina. 2006; 26(2): 191-195. doi: 10.1097/00006982-200602000-00012

34. Hsu J. Minimizing the risk of endophthalmitis after injection. Ophthalmol Retina. 2019; 3(1): 1-2. doi: 10.1016/j.oret.2018.10.011

35. Hsu J, Gerstenblith AT, Garg SJ, Vander JF. Conjunctival flora antibiotic resistance patterns after serial intravitreal injections without postinjection topical antibiotics. Am J Ophtalmol. 2014; 157(3): 514-518. doi: 10.1016/j.ajo.2013.10.003

36. Lanker Klossner B, Widmer HR, Frey F. Nondevelopment of resistance by bacteria during hospital use of povidone-iodine. Dermatology. 1997; 195(Suppl 2): 10-13. doi: 10.1159/000246024

37. Friedman DA, Mason III JO, Emond T, MsGwinJr G. Povidone-iodine contact time and lid speculum use during intravitreal injection. Retina. 2013; 33(5): 975-981. doi: 10.1097/ IAE.0b013e3182877585

38. Levinson JD, Garfunkel RA, Berinstein DM, et al. Timing of povidone iodine application to reduce the risk of endophthalmitis after intravitreal injections. Ophthalmol Retina. 2018; 2(7): 654-658. doi: 10.1016/j.oret.2017.06.004

39. Koemer JC, George MJ, Meyer DR, et al. Povidone-iodine concentration and dosing in cataract surgery. Surv Ophthalmol. 2018; 63(6): 862-868. doi: 10.1016/j.survophthal.2018.05.002

40. Avery RL, Bakri SJ, Blumenkranz MS, et al. Intravitreal injection technique and monitoring: updated guidelines of an expert panel. Retina. 2014; 34 Suppl 12: S1-S18. doi: 10.1097/ IAE.0000000000000399

41. Diabetic Retinopathy Clinical Research Network. Scott IU, Edwards Ar, et al. A phase II randomized, clinical trial of intravitreal for diabetic macular edema. Ophthalmology. 2007; 114(10): 1860- 
1867. doi: 10.1016/j.ophtha.2007.05.062

42. Royal College of Ophthalmologists. Age-related macular degeneration: Giidelines for management. Web site. http:// www.rcophth.ac.uk/wp-content/uploads/2014/12/2013-SCI318-RCOphth-AMD-Guidelines-Sept-2013-FINAL-2.pdf. Accessed September 22, 2016.

43. American Academy of Ophthalmology. How to give intravitreal injections. Web site. https://www.aao.org/eyenet/article/ how-to-give-intravitreal-injections. Accessed September 22, 2016.

44. American Academy of Ophthalmology. Five things physicians and patients should question. Web site. http://www.choosingwisely. Org/societies/american-academy-of-ophthalmology/. Released February 21, 2013. Accessed September 22, 2016.

45. Meyer CH, Mennel S, Eter N. Endophthalmitis rate mit und ohnetopische post-operative antibiotikgabe nach intravitrealer Avastin-Injektion. Der Ophthalmologe. 2007; 104(11): 952-957. doi: 10.1007/s00347-007-1634-6

46. Casparis H, Wolfensberger TJ, Becker M, et al. Incidence of presumed endophthalmitis after intravitreal injection performed in the operating room: A retrospective multicenter study. Retina. 2014; 34(1): 12-17. doi: 10.1097/IAE.0b013e31829f74b0
47. Ramel JC, Bron AM, Isaico R, Meillon C, Binquet C, CreuzotGarcher C. Incidence of endophthalmitis after intravitreal injection: is antibiotic prophylaxis mandatory? J Fr Ophthalmol. 2014; 37(4): 273-279. doi: 10.1016/j.jfo.2014.01.003

48. Stranak Z, Veith M, Studeny P, Pencak M. The incidence of endophtalmitis after the application of intravitreal injections in FNKV with regard to various prophylactic antibiotic regimens [In: Czech]. Ceskea Slov Oftalmol. 2014; 70(5): 184-188.

49. FalavarjaniKG, Aghamirsalim M, Modarres M, et al. Endophthalmitis after resident-performed intravitreal bevacizumab injection. Can J Ophthalmol. 2015; 50(1): 33-36. doi: 10.1016/j. jcjo.2014.09.005

50. Pachuo MA, Sahto AA, Quraishi MH, Abbasi AM. Role of post-injection antibiotics after intravitrealbevacizumab injection in preventing endophthalmitis. Pak J Ophthalmol. 2015; 31: 41-47.

51. Bhavsar AR, Glassman AR, Stockdale CR, Jampol LM, Diabetic Retinopathy Clinical Research Network. Elimination of topical antibiotics for intravitreous injections and the importance of using povidone-iodine: Update from the DRCR.net. JAMA Ophthalmol. 2016; 134(10): 1181-1183. doi: 10.1001/jamaophthalmol.2016.2741 